\title{
Work-life balance as a predictor of organizational commitment: a multidimensional approach
}

\author{
Stefanus Rumangkit ${ }^{1}$ and $Z$ Zuriana ${ }^{1}$ \\ ${ }^{1}$ Management Program, Economics and Business Faculty, Institut Informatika dan Bisnis Darmajaya, Indonesia
}

\begin{abstract}
The article investigates the relationship between dimensions of work-life balance (time balance, involvement balance, and satisfaction balance) on organizational commitment. Employee at one of the hotels in Bandarlampung, Lampung, Indonesia, were surveyed and a total of 60 useable questionnaires were returned. We employed multiple regression analysis on those data and found that the time balance, involvement balance, and satisfaction balance positively affected the organizational commitment.
\end{abstract}

Keywords

work-life balance; time balance; involvement

balance; satisfaction

balance; organizational commitment

\section{INTRODUCTION}

Organizational commitment has become one of most significant issues in organizational behavior studies recently. Among several predictors of organizational commitment, scholars attention on work-life balance as the predictor of organizational commitment has been increased (for example, see Huang, Lawler, \& Lei, 2007; Azeem \& Akhtar, 2014).

However, previous studies mostly treated work-life balance as a single dimension. Furthermore, Johari et al (2016) suggested that the role of work-life balance as predictor of employee positive behavior is needed to be re-examine in different contexts.

Therefore, our study objective is to examine the role of work-life balance as predictor of organizational commitment using multidimensional approach. As suggested by Haar et al. (2014), work-life balance comprised of three dimensions: time balance; involvement balance; and satisfaction balance. The advantage to treat work-life balance as multidimensional construct is the researcher was able to find out more specifically the effect of work-life balance dimensions on the organizational commitment.

Furthermore, our study adopted suggestion from Johari et al (2016) to reexamine the role of work-life balance as predictor of organizational commitment in different context by focus on hospitality industry. The reason to focus on hospitality industry was rooted from study by Iverson and Deery (1997), which argued that hospitality industry is characterized with its turnover culture. It is expected that our research model could contribute to managers from hospitality sector to mitigate the turnover rates among their employees.

\section{LITERATURE REVIEW AND HYPOTHESES DEVELOPMENT}

\section{Work-life balance}

Work-life balance was defined as an employee effort to balance their work and family life (Daipuria \& Kakar, 2013). The concept of work-life balance was based on the employees who tried to balance work and family life so that the life of employees was perfect. The organizations had to facilitate the work-life balance in order to raise positive impact on employee, such as increase the motivation, reducing job stress, creating higher productivity, and minimizing turnover rates (Johari et al, 2017). Choudhury \& Jyotirmayee (2015) suggested that the worklife balance had three dimensions: time balance, involvement balance, and satisfaction balance. The time balance involved the time given by the company to do work in office and outside office. The involvement balance involved the employee psychological work and activities outside the work. Moreover, the satisfaction balance concerned with the level of the employee 
satisfaction so long as they felt in working and doing things outside of work.

\section{Organizational commitment}

The concept of organizational commitment was first introduced by Mowday in 1982. The organizational commitment was defined as the employee attitude on the organization including the organizational values and organizational goals. The organizational commitment has been assumed as the valuable company assets facilitating company to achieve its goals. Allen \& Meyer (1990) stated that the organizational commitment was a psychological attachment of the employees and the organization. Organizational commitment was one of most interesting issues in organizational behavior study since its role as determinant factors affecting employee turnover, employee discipline behavior, motivation, and performance. Allen \& Meyer (1990) divided the commitments into three categories: affective commitment, continuous commitment, and normative commitment. Affective commitment referred to the psychological attachment between the employee and the organization; continuous commitment referred to the consequences that employees should take, and normative commitment referred to the employee responsibility to stay in an organization.

\section{Time balance, involvement balance, satisfaction balance, and organizational commitment}

Zhang et al. (2012) stated that the currently organizations has been dealing with issues related to managing employee balance between work and family. This was because there was an imbalance of the work time and family time. As employees have long working hours, they were not able to do any activities outside working hours such as doing sports and recreation with family and gathering with friends. When the organization able to provide the work time balance to employees through job flexibility, employees experience time balance between the work and the activities outside the work. The work-life balance provided by the organization created the organizational commitment. Some previous studies support the notion that time balance positively affected the organizational commitment (Greenhaus et al., 2003; Mas-
Machuca et al., 2016; dan S \& K, 2011). Therefore, the first hypothesis of this study is:

\section{H1: Time balance positively affects organizational commitment.}

\section{Involvement balance and organizational commitment}

Involvement balance was one of the work-life balance dimensions that were able to be a factor affecting the organizational commitment. Involvement balance concerned with the employee psychological state on work and activity outside the work. When employees were involved in decision-making, non-formal corporate members, and formal and non-formal events, the company made employees have a high level of the organizational commitment. This was because the employees perceived that they were needed, valued, and considered by the company so that employees preferred to stay longer in the organization. The previous studies on the involvement balance that had an effect on the organizational commitment were Amrutha Varshini \& Ishwarya, (2014); Smith et al., (2016); dan Yadav, (2014). Thus, the second hypothesis is:

H2: Involvement balance positively affects organizational commitment.

\section{Satisfaction balance and organizational commitment}

One of the factors that determinates organizational commitment was the satisfaction perceived by employees. Satisfaction balance is an appropriate factor affecting the organizational commitment. Satisfaction balance referred to the level of the employee satisfaction with which the employee performed work and the activities outside work. As the organization provided the flexible time, the job sharing, the bonuses, sports facilities, and the children playroom facilities, the employee made employees feel the satisfaction balance because the employees felt the balance of the work activities and the activities outside the work so that the organizational commitment improved. The third hypothesis is:

H3: Satisfaction balance significant impact on commitment organizational. 
Table 1.

Validity test of work-life balance scale

\begin{tabular}{clccc}
\hline Variable & Question Items & Rcount & Rtable & Explanation \\
\hline & Question 1 & 0.540 & 0.361 & Valid \\
& Question 2 & 0.834 & 0.361 & Valid \\
& Question 3 & 0.787 & 0.361 & Valid \\
& Question 4 & 0.515 & 0.361 & Valid \\
& Question 5 & 0.429 & 0.361 & Valid \\
Work-Life Balance & Question 6 & 0.834 & 0.361 & Valid \\
& Question 7 & 0.802 & 0.361 & Valid \\
& Question 8 & 0.515 & 0.361 & Valid \\
& Question 9 & 0.540 & 0.361 & Valid \\
& Question 10 & 0.834 & 0.361 & Valid \\
& Question 11 & 0.834 & 0.361 & Valid \\
& Question 12 & 0.719 & 0.361 & Valid \\
\hline
\end{tabular}

Table 2.

Validity test of organizational commitment scale

\begin{tabular}{lcccc}
\hline Variable & Question Items & Rcount & Rtable & Explanation \\
\hline & Question 1 & 0.598 & 0.361 & Valid \\
& Question 2 & 0.495 & 0.361 & Valid \\
& Question 3 & 0.556 & 0.361 & Valid \\
& Question 4 & 0.661 & 0.361 & Valid \\
Organizational Commitment & Question 5 & 0.676 & 0.361 & Valid \\
& Question 6 & 0.672 & 0.361 & Valid \\
& Question 7 & 0.496 & 0.361 & Valid \\
& Question 8 & 0.409 & 0.361 & Valid \\
& Question 9 & 0.606 & 0.361 & Valid \\
\hline
\end{tabular}

\section{METHODS}

The object of our study was the employees of one of the hotel in Bandar Lampung, Lampung, Indonesia, as one of the hospitality business. The number of samples used in this study was 60 people. Work-life balance was measured by instrument developed by McDonal and Bredley (2005) with 12 questions addressing the three dimensions of work-life balance. The organizational commitment was measured by scale developed by Allen \& Meyer (1990) with 9 questions.

\section{RESULTS AND DISCUSSION}

We conducted two stages in analyzing the data: (1) performing validity and reliability test on the scales; and (2) testing the hypotheses through the multiple regression. The analytical tool used in this study was SPSS. The validity test was employed using product moment correlation. The pretest was cto 30 respondents with $\alpha=5 \%$ level of significance and $r_{\text {table }}$ value was 0.361 . The result of the validity test is represented in Table 1 and Table 2.

The results show that the instruments were valid. It is indicated by $R_{\text {count }}>R_{\text {table }}$. After conducting the validity test, the reliability test was carried out by looking at the Cronbach's Alpha and the result is illustrated in the Table 3.

The result of the multiple regression analysis as represented in Table 4 indicates that time balance positively affects organizational commitment $(\beta=2.124$; $\mathrm{p}<0,01)$. Thus, hypothesis 1 was supported; meaning that the if the organization provides work time balance through the job flexibility, the employee can do some activities such as family gathering and sports then they felt the time balance between the work and activities outside the work. The work-life balance provided by the organization created the organizational commitment. It is in line with the previous study conducted by Baral \& Bhargava, 2010 and Kinman \& Grant, 2011).

The second finding of this study was that the involvement balance positvely affects organizational commitment $(\beta=0,642$; $p<0,01)$. Thus, hypothesis 2 was supported. The involvement balance concerned with the employee psychological state in work and 
Table 3.

Reliability test

\begin{tabular}{lcc}
\hline Variables & Cronbach's Alpha & Explanation \\
\hline Work-life Balance & 0.836 & Very high \\
Organizational & 0.749 & High \\
Commitment & 0.74 & \\
\hline
\end{tabular}

Table 4.

The effects of work-life balance dimensions on organizational commitment

\begin{tabular}{lrl}
\hline Dimension & $\boldsymbol{\beta}$ & Sig. \\
\hline (Constant) & 27.153 & .001 \\
Time Balance & 2.124 & .000 \\
Involvement Balance & .642 & .001 \\
Satisfaction Balance & .286 & .000 \\
\hline
\end{tabular}

activity outside of the work. As the employees were involved in decision-making, in nonformal corporate members, and in formal and non-formal events, the company made the employees have a high level of organizational commitment. This was because the employees felt that they were needed, valued, and considered by the company so that the employees considerate to stay longer in the organization. It supported the previous studies conducted by Talukder et al. (2018) and Lewis \& Humbert (2010).

The last finding of this study was that the satisfaction balance positively affects organizational commitment $(\beta=0,286$; $p<0,01)$. The satisfaction balance referred to the level of the employee satisfaction on which the employees had done the work and activities outside of the work. The organizations that provide flexible time, job sharing, bonuses, sports facilities, and children's playroom facilities make the employees felt the satisfaction balance because the employees were able to balance their work and the activities outside the work so that the organizational commitment improved. It supported the previous study conducted by Elangovan (2001); Sreejesh et al. (2019).

\section{CONCLUSION}

Our study confirmed that the dimensions of work-life balance (time balance, involvement balance, and satisfaction balance) positively affects organizational commitment. It gives the managers insights to be more focus on providing those dimensions in order to increase the employee commitment and furthermore reduce the turnover rate. Although have some contributions our study had some limitations; (1) the sample used was too small and was not able to be generalized; and (2) the organizational commitment was dimensionally not measured. Therefore, the future study is suggested to conduct on the same theme, the same variables, and the same approach.

\section{REFERENCES}

Agarwal, S., \& Lenka, U. (2015). Study on worklife balance of women entrepreneurs review and research agenda. Industrial and Commercial Training. https://doi.org/10.1108/lCT-01-2015-0006

Allen, N.J., \& Meyer, J. P. (1990). Organizational Commitment-Allen-Meyer (1990).pdf. Journal of Occupational Psychology. https://doi.org/10.1111/j.14610248.2012.01813.x

Amrutha Varshini, V., \& Ishwarya, J. (2014). Worklife balance among women employees in banking sector- a study at state bank of Mysore, Mysore. Tactful Management Research Journal.

Aydin, A., Sarıer, Y., \& Uysal, Ş. (2011). The Effect of Gender on Organizational Commitment of Teachers: A Meta Analytic Analysis. Educational Sciences: Theory and Practice, 11, 628-632.

Azeem, S. M., \& Akhtar, N. (2014). The influence of work life balance and job satisfaction on organizational commitment of healthcare employees. International Journal of Human Resource Studies, 4(2), 18.

Baral, R., \& Bhargava, S. (2010). Work-family 
enrichment as a mediator between organizational interventions for work-life balance and job outcomes. Journal of Managerial Psychology. https://doi.org/10.1108/026839410110237 49

Choudhury, \& Jyotirmayee. (2015). Quality of Work - Life Balance: A Study on IT Professionals. ASBM Journal of Management.

Daipuria, P., \& Kakar, D. (2013). WORK-LIFE BALANCE FOR WORKING PARENTS: PERSPECTIVES AND STRATEGIES. Journal of Strategic Human Resource Management.

Elangovan, A. R. (2001). Causal ordering of stress, satisfaction and commitment, and intention to quit: a structural equations analysis. Leadership \& Organization Development Journal, 22(4), 159-165. https://doi.org/10.1108/014377301103950 51

Greenhaus, J. H., Collins, K. M., \& Shaw, J. D. (2003). The relation between work-family balance and quality of life. Journal of Vocational Behavior. https://doi.org/10.1016/S00018791(02)00042-8

Haar, J. M., Russo, M., Suñe, A., \& OllierMalaterre, A. (2014). Outcomes of worklife balance on job satisfaction, life satisfaction and mental health: A study across seven cultures. Journal of Vocational Behavior. https://doi.org/10.1016/j.jvb.2014.08.010

Huang, T. C., Lawler, J., \& Lei, C. Y. (2007). The effects of quality of work life on commitment and turnover intention. Social Behavior and Personality: an international journal, 35(6), 735-750.

Iverson, R. D., \& Deery, M. (1997). Turnover culture in the hospitality industry. Human Resource Management Journal, 7(4), 7182.

Johari, J., Yean Tan, F., \& Tjik Zulkarnain, Z. I. (2017). Autonomy, workload, work-life balance and job performance among teachers. International Journal of Educational Management, 32(1), 107120. https://doi.org/10.1108/lJEM-102016-0226

Kinman, G., \& Grant, L. (2011). Exploring stress resilience in trainee social workers: The role of emotional and social competencies. British Journal of Social Work. https://doi.org/10.1093/bjsw/bcq088

Lewis, S., \& Humbert, L. (2010). Discourse or reality?: "Work-life balance", flexible working policies and the gendered organization. Equality, Diversity and Inclusion: An International Journal. https://doi.org/10.1108/026101510110288 40

Mas-Machuca, M., Berbegal-Mirabent, J., \& Alegre, I. (2016). Work-life balance and its relationship with organizational pride and job satisfaction. Journal of Managerial Psychology. https://doi.org/10.1108/JMP-09-20140272

S, S., \& K, J. (2011). Work-Life Balance: The Key driver of employee engagement. Asian Journal of Management Research.

Smith, K. T., Smith, L. M., \& Brower, T. R. (2016). How work-life balance, job performance, and ethics connect: Perspectives of current and future accountants. Research on Professional Responsibility and Ethics in Accounting. https://doi.org/10.1108/S1574076520160000020008

Sreejesh, S., Sarkar, J. G., Sarkar, A., \& Anusree, M. R. (2019). Investigating the roles of hotel brand relationship norms in generating relationship satisfaction and commitment. International Journal of Contemporary Hospitality Management. https://doi.org/10.1108/IJCHM-07-20170394

Talukder, A. K. M., Vickers, M., \& Khan, A. (2018). Supervisor support and work-life balance: Impacts on job performance in the Australian financial sector. Personnel Review, 47(3), 727-744. https://doi.org/10.1108/PR-12-2016-0314

Yadav, N. (2014). Comparison of the work life balance of women employees in educational field (degree colleges permanent employees) and IT industries. SIES Journal Of Management.

Zhang, M., Griffeth, R. W., \& Fried, D. D. (2012). Work-family conflict and individual consequences. Journal of Managerial Psychology. https://doi.org/10.1108/026839412112595 20 